\title{
ANGEL GANIVET Y SU CORRESPONDENCIA INÉDITA GON FRANCISCO NAVARRO LEDESMA
}

Dentro del ejercicio epistolar, al que los escritores españoles nunca han sido particularmente adeptos, caben mencionarse las cartas que Ángel Ganivet cruzó con Francisco Navarro Ledesma ${ }^{1}$ como una de las mejores manifestaciones anímicas y ontológicas de la España finisecular. Esta correspondencia, que inexplicablemente permanece inédita casi en su totalidad ${ }^{2}$, nos indica fielmente el

1 Gracias a la gentileza excepcional de doña Gabriela de Cubas Bliss, sobrina carnal de Francisco Navarro Ledesma ý legataria absoluta de sus cartas, he podido entrar en el examen minucioso de estos documentos que, indudablemente, me han ayudado a enriquecer el texto de mi libro Las novelas de Ángel Ganivet, Anaya Publishing Co., New York, 1972. Aquí saco a relucir muchos pasajes de esta correspondencia, sobre todo en lo que atañe a los años novelísticos del autor granadino y a las relaciones que mantuvo con la madre de sus hijos, Amelia Roldán.-Dentro de las limitaciones del presente estudio, acentuadas por el voluminoso material puesto a mi disposición, he tratado de favorecer las reacciones intimas de Ganivet, su evolución psicológicá desde $1890 \mathrm{y}$ todos los pormenores relacionados con la Roldán, que desgraciadamente no abundan. He desechado, no obstante, referencias directas a la España finisecular y a la política, que tanto el granadino como su corresponsal reiteran sin ninguna timidez. La razón de este "parti pris" es que el sentimiento noventayochista está muy presente en las cartas que Navarro publicó en el Epistolario y en las que se reprodujeron en $R O c c$, 11 (1965), 273-323, y que esta percepción de Ganivet osciló poco durante su vida. Un simple cotejo entre la tesis universitaria España filosófica contemporánea y las últimas cartas (1895-1898) de la recopilación prueban convincentemente esta semejanza.-Es recomendable, para una mejor comprensión de las presentes páginas, consultar las dos colecciones epistolares citadas, además de estos dos volúmenes: Juicio de Ángel Ganivet sobre su obra litéraria, cartas inéditas publicadas por Luis SECo DE LuCENA, Granada, 1962, y Correspondencia familiar de Ángel Ganivet (1888-1897), anotada por JAvier HERRERo, Granada, 1967. Véase también mi estudio Las novelas..., op. cit.

2 El material reproducido en el Epistolario resulta ser el de interés más generalizado, y se refiere, en parte, a la génesis creativa de Ganivet. Constituye mayormente una sugerencia fiel de lo que fueron los años preparatorios a la gran crisis espiritual del autor granadino, pero desafortunadamente Navarro quiso omitir sus propias cartas, lo que causa cierto vacío en la lec- 
curso entrañable que siguieron esas relaciones, aun en los instantes más críticos. Desde la nota inicial que se conserva en dicho epistolario ${ }^{3}$, garabateada por el autor granadino alrededor del 26 de junio de 1890, hasta las líneas postreras del 18 de noviembre de 1898 , que Ganivet redacta de una manera bastante indiferente, la correspondencia atraviesa toda una gama de matices afectuosos, reacciones defensivas y contrastes psicológicos que deparan un verdadero arsenal de conocimientos para el estudioso de la época. Resultan copiosos los pasajes que trazan los sentimientos de impotencia y pesimismo nacionales por que atraviesan aquellos que serán los portavoces del 98 , generación a la que ambos amigos se asocian de modo bastante premonitorio interpretando en sus menores detalles la lasitud general.

En una crítica estructural de la expresión epistolar ganivetiana valdría la pena, por ejemplo, citar los apelativos con que se encabezan las cartas; las dos primeras llaman al amigo por el apellido, pero muy pronto, a la tercera, comienza una familiaridad creciente que incluirá, durante 1890, nombres como Paco, Nepotes, Viajero, Paquimitimo, Curro, con súbitos regresos a varios "querido Navarro" que ya sugieren un estrecho afecto. En 1891, Ganivet estabilizará el tratamiento que, bajo rarísimas excepciones, persistirá en un "querido Paco", y, a partir de este período, la redacción tenderá a trasuntar un carácter más formal de su parte. El epistolario, tomado en su integridad, denota la reticencia de ambos escritores hacia la explotación de pormenores íntimos concernientes a devaneos sensuales, si bien esto no les impedirá discutir minuciosamente los estragos que causa una vida disoluta. Existe, empero, una carta sin fecha, puesta en la recopilación en el año 1890 (y con razón, por el tono), que presenta un momento exclusivo de Ganivet, quien relata mediante ciertos ornamentos las vicisitudes de "una noche de órdago".

Junto a esta misiva llena de floridas alusiones aparece otra, a continuación, donde el granadino alienta a Navarro, que soporta

tura, pues no se llega a situar claramente el estado recíproco de ambos escritores. Algo similar ha sucedido con la segunda serie epistolar aparecida en $R O c c$; en este caso, empero, algunas páginas poseen un carácter personal y obvio que logra explicar hasta cierto punto la estructura temperamental ganivetiana. Agreguemos que la mayor preocupación de Francisco Navarro Ledesma fue proteger la vida intima de su amigo, cuyas opiniones, además, hubieran podido ponerlo en pugna con la sociedad de la época. De ahí que muchos críticos hayan tomado por ignorancia suya lo que simplemente tradujo una elegante expresión de amistad. Véase mi libro Las notelas..., op. cit., nota preliminar.

3 Durante este trabajo toda referencia al epistolario aludirá a la correspondencia entera de Ganivet con Navarro; cuando se trate de la selección publicada por este último, figurará el mismo título, pero con mayúscula (Epistolario). 
algunas incomodidades morales y económicas, aduciendo que todo lo que le ocurre "es una bicoca; mucho más" ha sufrido él". Son las primeras líneas que denotan rasgos depresivos, cuya intensidad se irá acentuando a lo largo de los años: "Te duele el estómago y a mí la cabeza que es el órgano más importante y también mi estómago anda beefsteakeado horrorosamente... Has pensado en el suicidio y yo estoy aburrido de pensar y hasta deseché la idea, no quedándome hoy ese placer. $\mathrm{Y}$ sin embargo yo no me aburro como tú y soy superior a ti todo en virtud del estoicismo bendito por siempre". Viene con la carta un Iargo poema, Epistola moral, en el que Ganivet pretende socorrer el ánimo de su amigo ${ }^{5}$. Poco después, aún en 1890, compondrá unos párrafos que definen elocuentemente la batalla anímica que librará en los penosos momentos de Amberes y Riga:

Hoy me he levantado triste no sé por qué y te escribo no ya triste sino endemoniado.

Debe ser cosa de clima, porque hoy llueve y hace frío desagradable, pero a mí me tiene sin cuidado la causa y me fijo sólo en el efecto, que es como ya te digo estar completamente jodido. No es esto tampoco hablando con propiedad, pero no encuentro otra palabra: aburrido, hastiado, malhumorado, melancólico, abrumado, entontecido... creo que es todo esto junto y algo más ${ }^{6}$.

Y todo quizás sea por faltarme las creencias. ¿Sabes tú si los creyentes no están nunca abroncados? Porque entonces yo creería en algo aunque me costase trabajo, pues en verdad te digo, que con este escepticismo, nada que no puede uno estar tranquilo.

Gracias que provisionalmente cuento con el estoicismo que me hace terminar riendo la carta que comencé llorando, y me permito enviarte riecitos de paz y de tranquilidad a ti que seguramente es-

4 Las palabras en cursiva, en esta cita y en todas las siguientes, están subrayadas en el original. Por lo demás, mis transcripciones son textuales, y no me entrometo en enmiendas de errores ortográficos o de puntuación.

5 Puede verse el tono de la composición en estos versos: "Leyendo los amargos pensamientos / En que expresas, con gran fuerza y relieve, / Tus ideas, que más bien son lamentos, / Mi cerebro se excita y se conmueve / Al choque de penosas impresiones; / Que aunque estoico, no soy hombre de nieve".

6 Estos incipientes sintomas esquizoides de Ganivet, que se repetirán de modo crucial y enfático hasta su muerte, han provisto ciertos elementos justificativos a la teoría de una locura de origen sifilítico. Pueden corresponder, sin embargo, junto con otras reacciones presentes en el granadino, a un desarreglo del metabolismo, como lo digo en Las novelas..., op. cit., nota 12, pp. 27-28. Esto no refuta en nada la probabilidad de que el autor haya contraido en plena juventud el treponema, pero sí ayudaría a esclarecer el hecho de que gozó de entera lucidez hasta su suicidio. En algunas cartas de 1890 existen referencias continuas al tratamiento de la blenorragia, las que Ganivet comunica, a menudo de modo jovial, a Navarro, intimando con ello mucha experiencia personal sobre la materia. 
tarás triste en tu destierro a solas con recuerdos que acaso sean desagradables...

Faltan en la recopilación las cartas de Navarro Ledesma redactadas en 1890, pero ya al año siguiente comienzan a figurar las ilustradoras "causeries du lundi" que aquél dirigirá a Ganivet, al principio regularmente, todos los lunes, desde Argés, Toledo. La primera de estas "causeries" es del 6 de julio de 1891; y en la respuesta (Granada, 10 de julio de 1891) menciona Ganivet un ejercicio literario del que lleva escritas "51 cuartillas muy apretadas, en las cuales aparece un cuadro de costumbres granadinas". La novedad, seguramente primicia del arte creativo ganivetiano, constituye el producto de la determinación del autor en seguir un programa diario estricto, después de haber sufrido oposiciones universitarias que no ganó. A la vez transparenta el género literario al que Navarro se entregará en la correspondencia: breves relatos que poseen cierto carácter experimental y en los que sobresale un estilo impresionista mezclado con recuerdos personales. Existen diferencias, sin embargo, en ambos tonos epistolares, y para definirlas recorramos estas líneas de Ganivet, del 16 de julio de 1891:

Me ha complacido intimamente tu "causerie" y me ha hecho pensar una vez más en la ley de los contrastes, que se muestra patente en nuestras correspondencias. Tú, dedicado a la maniobra de componer un libro de texto, tienes "esprit" almacenado en abundancia y lo derramas con profusión... y puedes enorgullecerte de proporcionar un rato te solaz a quienes tienen la fortuna de leerte y comprenderte; yo en cambio, consagrado a trabajos puramente imaginativos dejo en ellos todo mi jugo y soy seco y desabrido cuando tomo la pluma para llenar algunos de los menesteres rutinarios de la vida, aunque éstos sean a veces tan gratos como escribir a quien, como tú, me zahiere porque me estima y me hace burlas, porque me cree a cubierto de ellas.

En efecto, a partir del verano de 1891, Navarro incursionará más y más por el terreno humorístico mientras que los signos de pesimismo e introversión de Ganivet se van agudizando, aunque de vez en cuando prodigue a su amigo divertidos pasajes y anotaciones. Sus cartas ya no traen los pintorescos encabezamientos del año anterior y puede percibirse cierto sentimiento de culpabilidad tocante a la sucesión de quejas, que empiezan a ser formidables. El 16 de julio el granadino se apronta a partir de excursión a Alfacar y la sierra, viaje que describe cuidadosamente a Navarro y donde apuntan los caracteres esenciales del famoso episodio de Pío Cid en Los trabajos?. Podría sacarse del retrato que traza de uno de

7 En el curso de este artículo me referiré a las novelas de Ganivet $L a$ conquista del reino de Maya por el último conquistador español Pío Cid y 
sus guías, originario de Berchul, la inspiración puesta en concebir al "tío Rentero" de la novela:

E1 Berchuleño es un viejo avispado, tan ruin de aspecto como prolífero para crear; hace unos cuantos años abandonó su pueblo nativo cargado con doce hijos pequeños y hace otros tantos que riega con sus sudores las tierras frías e ingratas de la Sierra, habiendo obtenido como premio el placer de sacar a sus hijos de culero y dar a algunos estado. Como todos los alpujarreños es trabajador, económico hasta la miseria, gran hablador y muy cuco para ver el lado práctico de las cosas; él es el que anima mis débiles aficiones agrícolas...

Luego consagra una prolija página costumbrista a la comida de una familia del lugar y termina con una referencia al admirable Veleta, adornado "con su blanca peluca que se desata en caireles o bucles rizados, según va derritiéndose la nieve"8.

La franqueza penetrante de Navarro, que abundará en la correspondencia, puede haber suscitado algún remordimiento personal de acuerdo a estas palabras que de Toledo aquél dirige a Ganivet el 27 de julio: “¿Cómo no he recibido carta tuya? No me atrevo a sospechar si te habrá amoscado mi rudeza. Creo que tu reino, como el mío y el de N.S.J.C., no es de este mundo, pero creo también en los extraños e incomprehensibles caprichos del amor propio". Acto seguido Navarro se refiere a un "contubernio" que, iniciado en la corte, persiste "dando sus sazonados frutos con tal prodigalidad que me destroncaría de vez, si no fuese por las repetidas ausencias que el cumplimiento del deber oficial me obliga..." Y continúa:

Lo que confirmo con placer y con la intima convicción de la experiencia personal, incomparable fuente del saber, es... la fuerza invencible del hábito y su asombroso vigor modificativo... Por la simple repetición normal y acompasada del acto hago heroicidades que ya creí para siempre enterradas entre las tinieblas de mi período eoceno: tales las hay que no son para contadas, ni aun en esta especie de fraternal comunión, esotérica de verdad, a la cual no deben llegar ni siquiera acercarse ojos profanos.

Los trabajos del infatigable creador Pio Cid, con los títulos abreviados La conquista y Los trabajos respectivamente.

8 Es de notar que si en el pasaje descrito encontramos diferentes rasgos de la excursión a la Sierra y al Veleta incluida en Los trabajos, ya en 1890 Ganivet saca a relucir en la correspondencia que nos ocupa las expediciones africanas de Emir y de Stanley, además de ridiculizar a la sociedad congolesa. Éstos son los datos más lejanos que hemos podido establecer acerca del posible germen de La conquista. 
Estas alusiones constituirán a menudo los velados umbrales a los que llegan las confidencias sensuales de ambos amigos, que debían reservar los detalles, a lo menos en esa época, para cuando se veían ${ }^{9}$. En la respuesta a la carta, fechada el 31 de julio, el granadino hace gala nuevamente de discreción omitiendo los efectos de una normal curiosidad al respecto y se limita a defender su entereza emotiva, su susceptibilidad, a la que ignora; la cual, según él, no reconoce los dardos críticos de Navarro y ya desprecia los futuros: "Pero conformando muy gustosamente con mi natural templado y flexible como el acero toledano, paso por alto tu sospecha de que yo me haya amoscado, o dejado extraviar por los caprichos del amor propio. ¿Válgame Dios, con el pobre mosquito y cómo cree que sus pisadas han de molestar al elefante!"

Las excursiones a la Sierra parecen haber continuado durante ese verano, aunque, fuera de la mencionada, ninguna otra merece de Ganivet un aparte esencial. Sólo leeremos rápidas indicaciones topográficas junto a sugerencias de tipo amatorio, que provocarán sospechas de devaneos al corresponsal de Toledo. Este se referirá puntualmente, al final del estío, a la falta de dinero que experimenta, al aburrimiento que le depara la ciudad donde vive y a los progresos hechos en su lucha contra una blenorragia proveniente sin duda de sus días madrileños. Por unas líneas que datan del 6 de agosto sabemos que Ganivet ha vuelto a la corte y que ocupa su antiguo cuarto en la casa de pensión de doña Angelita. Ocurre en esta carta un momento de irritación hacia el amigo que le hace exclamar:

...creo que debe haber alguna diferencia entre lo público y lo íntimo y que esto último debe llevar más fuertemente impreso el sello de la espontaneidad, dado que sea preciso constantemente depositar en el seno de alguien el secreto, que nos mortifica y que pugna por romper las mallas que lo aprisionan. Tú eres franco tratándose de hechos aunque éstos te afecten en lo más hondo, pero en cuestión de ideas o sistematismos eres más falso que yo, que es cuanto hay que decir. La diferencia entre ambos (permiteme siquiera por esta vez que una y empareje nuestras personalidades) está en que yo no tengo ningún sistema y los sostengo todos al compás de la conveniencia y tú dices no tener ninguno ni aptitud siquiera para sostener alguno per accidens y en el fondo eres el hombre más sistemático que conozco ${ }^{10}$.

9 Cotejemos el tono de las líneas transcritas con estas frases de Ganivet en carta de Amberes, 19 de mayo de 1894: "Desde hace tiempo me limito, siempre que es posible, a los preámbulos, a las suertes de adorno; pero como toro con resabios, cuando me citan a la suerte me escupo. Busco el bulto y no lo encuentro..." (Epistolario, ed. Aguilar, 3a ed., p. 971).

10 Esta carta, como las siguientes, está fechada del Ateneo de Madrid. En contadísimas oportunidades el granadino se volverá tan explícito en rela- 
Días después, el 24 de agosto, mentará entre citaciones griegas las consecuencias de su escepticismo: "Pero inútiles son todos los clamores cuando el que ha de escucharlos es sordo; el escepticismo nos hiere rudamente en todo nuestro ser y así caminamos por estos desiertos habitados con el corazón traspasado y la mente acongojada por la duda... Generalmente, si aspiramos a la gloria, no la conseguimos en tanto que no tomamos como instrumento para alcanzarla el mismo que causa nuestro martirio."

Sobreviene ahora, en la "causerie" que Navarro le dirige ese mismo día ${ }^{11}$, un pasaje fundamental cuya interpretación exacta resulta compleja debido al tono empleado. Ante los dolores de cabeza y descargas hepáticas que Ganivet documenta con minucia, su amigo responde: "Lo que tienes, lo mismo en el cerebro que en los órganos de escalera abajo es una sífilis proteica supraunzanganga que no puedes lamerte. En esta creencia abunda el amigo Cubas..." Hasta este instante, todos los medicamentos recomendados en el epistolario son para la blenorragia de Navarro y no existe ninguna sugerencia de que el granadino esté pasando por trances similares, fuera de que su conocimiento de farmacéutica aplicada denota un cúmulo de experiencia. Las frases transcritas resultan bastante vagas si se considera que los síntomas y deterioros del treponema están siendo suficientemente indelebles como

ción a sus llamadas "contradicciones", que llegarán a constituir la base de su arte novelístico y de ensayista. Tratará en la misiva que nos ocupa sobre dos puntos de interés para todo ganivetista; uno es el religioso cuando alude a un cura con quien ha hecho el viaje en tren: "Desde Córdoba a Alcazar el de! oficio divino y yo hablamos y yo procuré abrirle los ojos, diciendo atrocidades del clero madrileño; pero estoy convencido de que no los abrirá, porque le pesan mucho los párpados. Ni Cristo le saca de las flaquezas hu manas y de las ovejas descarriadas". Rematará la carta a Navarro confesando su ignorancia en literatura francesa, de la que su amigo tiene un conocimiento mayor (cf. Las novelas..., p. 52, n. 3).-En la respuesta, una "causerie du lundi" del 10 de agosto, Navarro exclamará: "Puede que hayas hecho ciento y mil: pero todavía no has dicho ninguna incoherencia, ni ningún contrasentido; se entiende, sustancioso, oportuno y artístico. $\mathrm{Y}$ cuando quieres decirlos resultas desmañado y patoso como un seminarista borracho". En la "causerie" siguiente, del 17 de agosto de 1891, leemos: "Fuera de coña, lo cierto es que en Madrid tienes más talento que cuando te hallas sujeto a la perniciosa influencia de los Zegríes de tu pueblo, que probablemente serán hoy bastante más bultos que los del tiempo de Ginés Pérez de Hita".

11 Navarro persiste en fechar los lunes sus "causeries", pero a partir de ésta del 24 de agosto se retrasa un día; y en la del 31, escrita seguramente el 19 de septiembre, comenta: "Efectivamente al principio lo eran du lundi. Empero tout passe, tout casse, tout lasse. Se hicieron du mardi... conservando el primer título". Después los retrasos serán más y más obvios. - En la "causerie" del 24 de agosto aparecen algunas líneas despectivas hacia la Pardo Bazán, "mi ilustre amiga... que no pasa de folletinista cursi". Actitud muy semejante, por otra parte, a la de Ganivet con respecto a Unamuno. (Cf. Las novelas..., p. 48 , nota 45 .) 
para haber convencido a Cubas de su presencia. No obstante, cuando Ganivet contesta, el 27 de agosto, aborda el tópico de modo a conducirnos hacia el criterio de Cubas:

Y ya que hablo de mi condición patológica te diré que quisiera tener el genio musical.. para llenar el espacio infinito con una avasalladora y espeluznante Marcha triunfal a la Naturaleza humana. Yo que soy testigo imparcial de la guerra encarnizada que la mía está sosteniendo con una formidable conjunción de elementos cómicos y microscópicos, y de fuerzas interiores, traidoramente vendidas al enemigo, yo que sigo con curiosidad interesada las alternativas de la contienda, las falsas retiradas, las efímeras victorias, los avances inesperados, acechanzas, las traiciones, las muertes fingidas y las resurrecciones repentinas de zorra astuta, puedo proclamar a grito pelado las dotes inapreciadas de nuestra naturaleza; su conciencia biológica; su esfuerzo en el combate; su sabiduría terapéutica, su constancia maravillosa que no flaquea hasta que se ve abandonada por su aliado espiritual, la voluntad, alma universal y esencia de todas las cosas, según Schopenhauer.

Nunca más, a lo largo de toda la correspondencia, apuntará este problema que, si fue real de acuerdo a algunos, epistolarmente sólo trajo consigo disquisiciones de género metafísico y anímico, una perspectiva muy personal de filosofía decadentista y a menudo un estado abúlico que el granadino compartió con Navarro. Es paradójico que desde este punto de vista la evolución espiritual de ambos escritores coincidió en infinidad de aspectos, y ya por 1896 cuesta separar sus respectivas individualidades.

La carta a Navarro del 31 de agosto contiene excelente material para el discernimiento de algunas fuentes de Los trabajos. En ella se refiere Ganivet a los "protoplasmas sociales", acerca de los cuales dice que si hay individuos "que en ciertos periodos de la vida no son nada concretamente y están por lo mismo en aptitud para serlo todo, así hay también sociedades, que como lo absoluto de Schelling, no son nada realmente y poseen, en su indeterminación, capacidad para serlo todo, lo más vario y lo más opuesto. A estas sociedades se las podría denominar protoplasmas colectivos o formas conglomeradas de la voluntad abstracta o manifestaciones colectivas de lo Inconsciente, etc..." 12 . Un breve relato que acompaña a estas líneas, intitulado Candidito ${ }^{13}$, presenta a Navarro en su medio habitual, Toledo, rodeado de su familia y lleno de mimos, pero incapaz de alcanzar la felicidad pues es demasiado penetrante:

12 Compárese esta definición con la estética realista-naturalista de El protoplasma, episodio independiente de Los trabajos.

13 En Las novelas..., p. 143, nota 80, hago referencia al aspecto autobiográfico del personaje. 
"Este joven tiene sólo la desgracia de que ve el mundo distintc de como lo vemos los demás. ¿Tiene ahumados los cristales de sus quevedos? No hay tal humo. Este joven, aunque a primera vista no ve más que nosotros, en realidad alarga un poco más y ahí tiene la causa de su desgracia... [Pobre Candidito! Te veo condenado a vivir en el desierto de los hombres, que es mil veces más triste que el desierto de las arenas"14. Días después, el 9 de septiembre, Ganivet se expresará por primera vez en la correspondencia, y contundentemente, sobre aspectos estéticos tocantes a la coherencia literaria. Su posición se resume en un solapado ataque a la desunión entre los elementos integrantes de una obra:

Conviene pues que el artista, y muy principalmente el subjetivo, el impresionista, el crítico no se limite a combinar, a ordenar impresiones, ideas artísticas; deben fundirlas reflexivamente, unificándolas, si aspiran a producir algo bello... Aunque la personalidad del artista estuviese significada por su desequilibrio constante, por la imposibilidad de unir los varios aspectos fugaces, inestables de su espíritu (esto realmente no es posible), aún así, sus creaciones artísticas deberán tener unidad, porque las palabras arte e irreflexión o espontaneidad son incompatibles. Cabe la espontaneidad en las manifestaciones espirituales que no llevan pretensiones artísticas y en la vida que, es un arte espontáneo... Si el arte no es espontáneo ni consiste en la simple coordinación de elementos artísticos, cómo es posible incluir dentro del arte lo incoherente? De ningún modo. No queda más escapatoria que suponer que la incoherencia es un procedimiento artístico; que la incoherencia no excluye el cumplimiento de ciertas condiciones imprescindibles para el arte. Pero es insensato suponer que la coherencia (menos aún que la unidad, que la armonía, que el color) pueda brotar de la incoherencia.

[Pocos lograrán] vislumbrar el espíritu superliterario que vaga entre los huecos de los pensamientos incoherentes. Fuera de éstos, no habrá quien dé el salto mortal necesario para pasar de lo que aparentemente es una sarta de tonterías a lo que podrá ser, si se quiere, una manifestación refinada, exquisita del arte. $Y$ tengo además por seguro que de cada centena de incoherentes pasarían por necios la mitad y el resto por ridículos o estrafalarios. Huyamos de los casos aislados, dejemos los procedimientos azarosos y sigamos el procedimiento natural y eterno de expresar la belleza con palabras ${ }^{15}$.

14 En la "causerie" que Navarro envía como respuesta añade algunos renglones acerca de $S u$ único hijo, que no le ha producido la menor impresión: "Desafío a la persona que con nervios más sensibles se crea a sentir siquiera el más leve estremecimiento papilar leyendo la cosa esa. En resumen, que se cae de pura sosería".

15 Debe hacerse aquí una clara distinción entre el apego que Ganivet mostró siempre hacia el desequilibrio mental de un personaje, usado como 
A la semana siguiente, el 15 de septiembre, proseguirá con la misma exposición:

El cuadro de las meninas huele a Velázquez; no es un conjunto de retazos tomados de la madre naturaleza, sino que es esto y algo más; y este algo más no brota allí espontáneamente (como pretendes tú que debe ocurrir) sino que está puesto por el artista, según el procedimiento técnico que bien le pareció... ¿Crees tú que si de varias incoherencias resulta una obra coherente (vamos a gastar la palabra) diría yo una santa palabra? No; el mal está en que varias incoherencias pequeñas produzcan una serie de ellas, sin el conjunto que el arte reclama... Reverencio a todos los iniciadores y soy fatalmente enemigo de seguir los caminos trillados, cuando hay otros por donde se vaya a alguna parte... Pero y si no hay más camino que el natural y eterno de expresar el pensamiento con palabras...

Vienen luego, bajo el título de Notes, dos páginas de Ganivet de carácter bastante obsceno, escritas en un francés defectuoso. Entre otras cosas aparece mencionada la próxima llegada de Navarro a Madrid, que viaja para examinarse de Derecho Mercantil por tercera vez. A los pocos días, éste ya estará de regreso en Argés y dirigirá al granadino una "causerie" que incluye unas quintillas llenas de mofa $^{16}$ que describen a la perfección el tono utilizado con Ganivet en la época. En la respuesta del 12 de octubre, el autor de

elemento artístico, y la incoherencia, sobre la que tiene reservas. Indudablemente, la "locura" puede constituir un interesante apoyo anímico dentro de un contexto desequilibrado mientras que la incoherencia es un tipo de expresión estética que el granadino sólo tolera en sus mejores logros. En la citada carta Ganivet recriminará a Navarro algo de "incoherencia" en sus escritos, y lo afirmará de un modo cuya paternidad podría reclamarla Pío Cid: "Hace algún tiempo te dije: «mucho hierro» porque andabas mal del estómago; y hoy te digo: «mucha lógica porque no andas mejor de la cabeza. La lógica y el hierro forman un matrimonio feliz y engendran las energías humanas que necesitamos para ir tirando de esta miseria que vive con nosotros".

16 Leemos también en la "causerie" del 5 de octubre, terminada el 8, los siguientes versos: "Días serenos de octubre / en que la vida, al pasar / impetuosa descubre / el misterio que se encubre / tras las nieblas del soñar: // días en que el sol alumbra / con claros fríos reflejos / la tenebrosa penumbra, / que allá, en lo alto se columbra, / de los olivares viejos. // Con sus luces invernales / los rayos horizontales / por entre las hojas largas / muestran en los cigarrales / las aceitunas amargas. // Aceituna es el placer; / brillante y tersa al nacer / la mordemos con deleite / y nos repugna al morder, / la amargura del aceite. // Porqué sufro y porqué vivo? / Porque, ya muy pronto espero, / que me arroje compasivo, / como el fruto del olivo / a la tolva el molinero". EI lector familiarizado con los versos de Ganivet, y el que haya recorrido las numerosas páginas llenas de consejos sobre composición poética que el granadino envió a Navarro, desentrañarán a primera vista un producto puramente ganivetiano en el poema transcrito. 
Los trabajos mienta indirectamente el episodio romántico, apenas anterior a su enamoramiento de Amelia Roldán, y del que ya ha hablado a su madre en una carta del 30 de septiembre ${ }^{17}$. Dice a Navarro: "Dispensa la sarta de consejos que te da quien acaso necesite de ellos muy pronto, aunque en otro sentido (presiento algo romántico, no sé por qué), pero no puede hacer otra cosa quien sin quererlo es llamado el P. G." La misiva del 24 de octubre comienza con lo que será el clásico desasosiego ganivetiano a partir de 1893: "Contesto a tu carta bajo la impresión más penosa que puedas imaginarte. Aunque no me ha sucedido nada de particular no deja de ser cierto que estoy muy triste, en primer término porque lo estoy y en segundo porque no sé por qué lo estoy. Tengo pocas fuerzas para escribir y experimento la sensación de que mi cabeza está vacía o que mi cerebro piensa sin yo darme cuenta de ello." Navarro, en su "causerie" del 30 de octubre, le aconseja que abandone la lectura de Janet, persuadido de que éste es el motivo de la depresión de Ganivet quien, desde hace unas semanas, está embebido en las obras del francés:

Lo repito: cuando me separo de ti, no haces más que necedades. Cuando no te metes en zarzueleos y orgías sosas, te sumerges en Janet. ¿Adónde bueno, con todo eso? ¿Cómo no has de aburrirte y entristecerte?... Lo que tú traes no puede ser más contrario a la higiene intelectual, única respetable. Esto no es gruñirte, sino recordarte la condición humana de que nos creemos adornados... Tales vicios y corruptelas de indole filosófica y'opositora te conduce a desbarrar enormemente...

A pesar de estas advertencias Ganivet persiste en sus estudios metafísicos que, sin duda, hacen modificar el epíteto de las "causeries" de Navarro quien las intitula "ésothériques" a partir del 9 de noviembre ${ }^{18}$.

Hacia finales del año la correspondencia se vuelve meticulosa en detalles tocantes a pequeñas deudas de Navarro, a novedades sobre oposiciones universitarias y a amistades en común. El 21 de diciembre, aquél recibe un Nocturno de Ganivet que termina con este párrafo: "Hecho in mente en la Puerta del Sol el día 12 de

17 Cf. Las novelas..., p. 133, nota 50. El presunto noviazgo debió ser cosa rapidísima, pues de otro modo Navarro, que acababa de estar en Madrid, se hubiese enterado. Ciertamente, todo ocurrió en los últimos días de septiembre, ya que el 30 de ese mes Ganivet declarará a la madre su decisión de no echarse novia.

18 En la "causerie" del 13 de noviembre Navarro expresa su gran admiración por Taine; en esa época trata de componer un manual de literatura y le parece que la historia de la literatura inglesa del crítico francés es un modelo tan magnífico que si Ganivet no logra conseguir los primeros tomos está decidido a encargarlos a París. 
diciembre a las 12 de la noche, cuando era víctima del aburrimiento más absoluto y me disponía a cometer alguna barbaridad"19. En otra carta del mismo día el granadino se referirá a una vaga sensación premonitoria: "Hay algo más doloroso que el dolor; el sentimiento de que nuestro dolor es ridículo. Esto ha podido decirlo un genio y sin embargo no lo ha dicho, que yo sepa. No quiero hablar de pesares porque me descompongo. He leído L'uomo de genio de Lombroso y he llegado a sospechar que yo soy genio, pero que no he tenido todavía ocasión para manifestarme; yo deseo que alguien se ofenda o me haga algo para coger la ocasión por los cabellos; yo necesito estimulantes..." Ocho días después, poseído de un estado de espíritu semejante al de sus últimos días, se da a una divagación sobre el conocimiento:

Se conoce no analizando, sino abstrayendo; cuando es mejor la abstracción es mayor la distancia entre la inteligencia y la realidad, y el juicio es más exacto, más sereno. He aquí un argumento en pro de la Metafísica que no he leído en ningún metafísico. ¿Y si yo te dijera que esta abstracción es dolor como es dolor la creación artística? No puede haber un hombre feliz y metafísioo a la vez. El sufrimiento hace ahondar en la realidad y penetra en su esencia. Se busca el placer en el fondo cuando la superficie de las cosas no molesta; y según se ahonda es la tristeza más profunda. Penetrar en la vida ideal es casarse con la melancolía.

A continuación surge, para diversión de Navarro, un diálogo muy ganivetiano en el que «Clarín» resulta ser la principal víctima: "Es que ese hombre es un tipo repugnante, sin que esto sea negarle su talento. Todos los tienen, pero, créame Ud. no tiene ni un amigo, ni puede tenerlo." (Estas palabras están dichas por Fray, el interlocutor imaginario de Ganivet.) Luego el granadino ensalza a Bonafoux, el archidetractor de «Clarín» ${ }^{20}$. Rematará el año epis-

19 "Nocturno (Ah! = rêvant à la chaise longue) // Vapores grises / Espesas neblinas / Caen, durmiendo, del cielo a la tierra; / Las noches tristes, / Como una agonía, / Me alegran. // E1 alma presa / En cerebro oscuro / Deja impresos muy débiles rastros; / Entre la niebla / El cuerpo, confuso / Va pasando. // Detalles vagos, / Las luces brillantes; / Indistintas, borrosas, las sombras; / Cruzan al lado; / Son todas iguales: / Seres, cosas. // Nos aprisionan / Las redes del aire / Nuestros sueños en nieblas se esconden; / Nadie las toca; / De los ojos delante / Siempre corren. // Los ojos torpes / Dan visiones débiles / Y la mente tranquila descansa / Ruidos discordes / Que de lejos vienen / Le aletargan."

20 La carta final del año, del 31 de diciembre, terminará con un elogio a Cánovas: "Según podrás notar por lo que va a escribir no me faltan hoy ni el discurso ni la expresión; digo lo que quiero y como quiero. La pluma obedece al pensamiento con canina sumisión y todo sale como una seda; y es que mi pensamiento está hecho un Cánovas y no hay menguado que le resista por estas veinticuatro horas..." 
tolar con un diálogo "fisio-psicológico" entre el corazón y el cerebro, en el que triunfa este último al responder: "Es que transformo el calor en pensamiento y pensar como parir es un trance muy amargo y doloroso. Tú en cambio transformas el frío amargo de mi experiencia en el calor que lleva consigo los irreflexivos entusiasmos y renueva los eternos deseos... La vida es una oleada de sangre que a ti te hace reír y a mí me hace llorar!"21

Ganivet inaugura 1892, año trascendental para él pues a las pocas semanas conocerá a Amelia Roldán y luego se radicará en el extranjero, con unas líneas ( 7 de enero) de sabor parecido al que presentarán muchos párrafos de La conquista: "Tiene el hombre, como tú sabes muy bien, virtualmente contenidos en su esencia méritos y deméritos que corresponden por derecho propio a otros animales de inferior consideración en los escalones zoológicos, y yo además me inclino a creer que a ningún animal se acerca tanto al hombre como el gato. Se parece más al mono, es verdad, pero este parecido es orgánico; parecido funcional es mayor el que tiene con la raza felina en sus especies domésticas." Luego, ignorante de lo que el destino le reserva en cuestión de días, agrega: "Yo no me conmuevo..., antes al contrario noto que mi corazón va adquiriendo consistencia berroqueña. Quizás convendría remojarlo con alguna cosa barata, un amor de taberna o cosa así, para que no se secara del todo... yo no sé qué parecerá un corazón convertido en algo así como olla de porcelana o destilador de aguas turbias, donde se realizan operaciones tan ingratas como preparar la comida y la bebida. Pues bien, il mio cor se va acercando a esto; aunque le arrimen la consabida estopa y sople con mil diablos sigue tan impávido..." El 5 de febrero redacta el párrafo donde ya anuncia a su modo el encuentro crucial con Amelia y su familia: "Culpa al amor y no a mí de mi silencio; cosas hondas y problemas trascendentales me han conturbado el espíritu. Hoy gracias a, no sé a quien, no a Dios en verdad, todo se halla resuelto sin que hayan padecido gravemente, la moral ni el Derecho, ni la higiene. Me da el corazón que has de aplaudirme cuando te hagas cargo de mi conducta, si es que en este caso yo he seguido alguna conducta" 22 . Desgraciadamente, ignoramos la reacción de Navarro pues a poco de llegar la carta se marcha a Madrid a hacer sus oposiciones. Habrá que esperar el principio de abril para que el intercambio epistolar sea reanudado con una "causerie ésothérique" fechada el 11 de ese mes. Podemos asegurar, no obstante, que Navarro, durante las semanas pasadas en la corte, se había convertido en presencia familiar para la Roldán ya que la "causerie" dice al final: "A Diotima-Amelia abrázala por tu cuenta una vez

21 Este diálogo también lleva fecha 31 de diciembre de 1891.

22 Sobre este episodio véase Las novelas..., pp. 132-134. 
más pues yo ni por correo me encuentro con fuerzas para abrazar a nadie" ${ }^{23}$. Hace constar en la frase, indudablemente, la vida disipada que lleva cada vez que va a Madrid, en la que a menudo contó como compañero a Ganivet, quien se dedicaba exclusivamente a su amigo aunque debiese descuidar a la Roldán.

EI 2 de mayo el granadino anuncia haber comenzado ya las oposiciones administrativas que le abrirán las puertas de la carrera diplomática, en las que entran en competencia doce concursantes. Menciona, además, las plazas vacantes y el sueldo: Argel $(18,000$ reales), Amberes (16,000 reales), Montreal, Hong-Kong y Shanghai $(30,000$ reales $)$, y le pide a Navarro que le escriba en francés de ahí en adelante a fin de poder practicarlo. La resolución es de breve plazo, y para la "causerie" del 19 de mayo aquél regresa al español sin mayores remordimientos al ver que Ganivet ya había tomado la misma decisión. En la primera carta en francés, del 6 de mayo, Navarro se dirige a "Monsieur le mari d'Alterego", tocando así la naciente liaison del amigo con Amelia. Aquí habla del viaje que emprenderán ambos amantes una vez que se terminen las oposiciones consulares, y por el tono oficial, si bien siempre jocoso, con que describe la relación llegamos a presentir un próximo enlace o por lo menos la intención formal de contraerlo. Viene en seguida una delirante "causerie", del 19 de mayo, que nos entera del triunfo de Ganivet, quien elige Amberes como destino consular; en carta del 25 de mayo de 1892 éste describe la partida de "Alterego" (Amelia Roldán) a Barcelona y la suya propia a Granada. Apenas llega pone' unas líneas a Navarro que son interesantes por resentirse el granadino de cierta tibieza en cuanto al pasado idilio. A raíz del casamiento de su prima, Ganivet comentará: "Mi suerte es que mientras en el resto de la familia hace progresos el espíritu casamentero, en la mía íntima sucede todo lo contrario, con lo cual estoy contentísimo. Si al llegar a mi casa veo algo parecido a lo que en casa de mi tía está pasando con el casamiento de mi prima te juro que tomo el tren y me vuelvo."

El 18 de junio ya está de regreso en Madrid y el 28 se pone en camino de Amberes vía Barcelona, donde se detiene a fin de visitar a Amelia: "Mandé a una criada a entregar algunas cosillas a

23 En la "causerie" del 14 de abril van unos versos a propósito de Amelia que indican la intimidad existente entre Navarro y Ganivet: "Esa ventaja tiene Ganivet; / que el físico le importa un cacahuet, / que para dar por satisfecha a Amelia / le sobra con la sal de Paz y Mélia / y, si no es tan hermoso como Apolo, / es tan bragado como el Discobólo, / que es lo que al caso importa / y lo que a la sensible Amelia embarga, / pues si, cual todo, nuestra vida es corta, / que alguna cosa al menos sea larga / y que sea esa cosa / el verbo de la cópula amorosa". (El erudito Antonio Paz y Mélia, conocido de ambos escritores, había publicado en 1890 la la serie de su colección de Sales españolas.) 
Alterego con cita para verla un momento en un restaurant. Apareció como un espectro; la dama de las Camelias en las últimas escenas... Yo tengo el consuelo de que con la enfermedad ha perdido la memoria y se olvidará de mí, y también tengo la seguridad de que dentro de algunos años habrá en todo esto que parece vulgar mucha poesía porque la hay" ${ }^{24}$. El 5 de julio llega a París, ciudad en la que experimenta un pasajero entusiasmo sensual por dos mujeres de vida ligera, Renée Block y Blanche Berthelot ${ }^{25}$. El 13 de julio llega a Amberes y se aloja en casa del canciller del Consulado español. Sus primeras noticias desde allí manifiestan idéntico carácter a las enviadas de París: frases sobre la arquitectura y ambiente de la ciudad y mayores pormenores acerca de las mujeres $^{26}$. Abruptamente, el 5 de agosto, Ganivet confiesa que sus nervios se han debilitado: “...no sé por qué, desde que vine he sufrido un cambio nuevo de temperamento y me he vuelto más nervioso que una histérica. Es una cosa rara y que no sé si atribuir a una reacción producida por el roce de esta flemática gente, o a una idea puramente subjetiva nacida de compararme con mi entourage o a una influencia efectiva del clima, de la alimentación, de las bebidas, etc." ${ }^{2 \tau}$ También alude a su choque inicial con el cónsul, "el número uno de los percebes", quién le ha reprochado haberse mezclado con el público durante un Te Deum. El 1\% de agosto se marcha de la casa del canciller, donde se ha hospedado temporalmente, mudándose a un departamento situado en Anselmo Straat, 18, frente al Palacio de Justicia "y muy cerca del Chaussée Malines, 53", donde está el Consulado de España: "Tengo un cuarto solo muy bonito, con tres balcones, a pocos pasos del boulevard

24 Carta de Barcelona, del 2 de julio de 1892. Es difícil descifrar a qué enfermedad alude, a menos que sea el primer embarazo de la mujer.

25 Las dos aventuras están descritas en detalle en la carta del 12 de julio, último día de Ganivet en París. - Resulta interesante ver la opinión que le merece la población de París: "El parisien es un hombre sin carácter, que se confunde con cualquier otro, salvo cierta clase poco numerosa, que viste mal y con descuido; pero la parisien, aun la de más baja estofa, es siempre distinguida, elegantísima y hasta espiritual, aunque esto de espiritual sea sólo exterior... Contrasta la delicadeza de las formas exteriores con la grosera degradación que hay por dentro, y viéndolas de cerca se comprende que ambas cosas sean necesarias y vayan siempre unidas" (carta del 10 de julio de 1892).

26 Navarro se quejará de ello en la "causerie" del 19 de julio: "Me describes Paris, al fin y al cabo / bajo un prisma tan solo, el de tu nabo, / hablándome, con cierta donosura / de tal cual vulgarísima aventura..." - En la "causerie" del 30 de julio le pide a Ganivet noticias más precisas sobre arte y estilo literario franceses, mayormente en lo que concierne al simbolismo.

27 Notese que Ganivet no anda muy descaminado al creer que una modificación del régimen alimenticio puede haber provocado la reacción. 
des Arts..." 28 Comunica que todos los gastos deben salir de su sueldo mensual de 305 francos.

En la "causerie" del 25 de agosto Navarro ruega a su amigo que le escriba cada dos días pues en España se han enterado de la epidemia de cólera que azota a Amberes y a Hamburgo. La contestación, que trae fecha del 25-30 de agosto, elude más o menos el tema y anuncia la primera página del trabajo "Socialismo y música". El 7 de septiembre el granadino compone unos párrafos fuertemente misóginos donde afirma entre otras cosas: "No hay tales mujeres finas y delicadas y desgraciado del que crea haber topado con una, porque no tardará en caerse en que como un idem se subiera. La finura y delicadeza de la mujer consiste en la distancia a que nos ponemos y se desvanecen según nos acercamos; y no es preciso llegar muy cerca para que desaparezcan por completo" ${ }^{29}$. En esa época conoce a una mujer, a quien llama frecuentemente

28 Carta del 10 de agosto de 1892. Ganivet ya comienza a descubrir las trampas del canciller, pero trata de protegerlo a medias a causa de la familia que aquél mantiene. A pesar de ello, hace participe al cónsul de las artimañas del canciller, actitud que Navarro desaprueba fuertemente en su "causerie" del 15 agosto, pues "la mitad de la ciencia está en saber callar y la mitad de la vida en no hacer o en dejar hacer a los otros y que a uno no le hagan". El mismo día, antes de haber recibido esa "causerie", Ganivet escribe que el canciller, en razón de su género de vida, "tendrá que descender desde donde ahora está (te advierto que vive a lo príncipe) merced a complacencias o compadrazgos que han terminado". Véase el agudo artículo de JAvier Herrero. "Ganivet y sư canciller en Amberes", RHM, 30 (1964), 27 I278. - En dicha carta el granadino pide a Navarro: "Hazme la bondad de guardar estos papeles en buen sitio... porque quiero que seas mi archivero, para que si algún día dejo este país y el libro de apuntes se me pierde, como así lo espero, no se pierda todo mi trabajo y mi tiempo". En realidad, este encargo fue cumplido puntualmente.

29 Esta carta trae, además, un pintoresco cuadro de lo que era la habitación del autor en Amberes: "Estoy sentado en un diván de espaldas a la calle; detrás de mí está la fachada formada por tres balcones, sin paredes intermedias, a la derecha el lavabo, la gran chimenea y una mesa con libros; a la izquierda la cama de palo no santo, la mesa de noche y un clavijero. La cama tiene amplísimas colgaduras; en frente un gran armario de luna, donde guardo la ropa y a la izquierda de él la puerta. A la derecha hay un gran testero donde tengo formando gran abanico los retratos de mi familia y variedad inmensa de cromos de flores, tipos y animales de todos los países. En los huecos diez sillas veraniegas y en el centro, cerca de mí, una mesa redonda en desorden: botellas de cerveza, una copa de cognac, mouchoirs, quinqué, libros, papeles secantes, cuartillas blancas y escritas, tintero, purera, cigarrera y palmatoria en una bandeja, fósforos al uso del país, ceniceros, reloj. Todo el cuarto está bien amueblado y con mediano comfort..." Luego detalla su régimen alimenticio: "Por la mañana todo va bien: a las nueve, té con leche, dos bollos con manteca y una copa de cognac; pero la comida fuerte es a las doce y a pesar de la infinidad de platos no me alimento bien, por cuestión de sistema; la comida de aquí es mantecosa... Por la noche a las siete ceno en casa cosas fiambres a mi gusto y me hincho de cerveza..." 
"Mlle. X", que lo fascina sólo hasta cierto punto, ya que su sentido antifeminista continúa fortaleciéndose:

Cuando las mujeres se limitan a vivir como han aprendido a vivir, encantan con su sencillez; cuando acostumbradas a una vida mejor de la que llevan soportan ésta con decoro y esforzándose porque el descenso natural no sea también descenso moral, seducen con mil pequeños rasgos de orgullo inocente y disculpable vanidad... Pero quitando lo que había de pasión justo es reconocer que la negación mía no es tan absoluta como parece, que yo también creo todavía en una pequeña patria, donde debe haber mujeres de ésas, que difícil te ha sido a ti encontrar y a mí imposible, salvo el hallazgo de Alterego, que a pesar de todos los pesares, tenía algo de eso, y a la que comparándola con las féminas de aquí, debo proclamar como volcán en actividad de todas las pasiones femeninas y archivo bien repleto de todas las gracias, finuras y delicadezas $^{30}$.

Adviértase que las citadas palabras constituyen el único testimonio verdaderamente elogioso para Amelia que se logra hallar en la documentación ganivetiana.

Hacia finales de ese año resaltan ya los síntomas iniciales de la misantropía que después prevalecerá en Ganivet. Escribe el 27 de octubre:

Según el modelo definitivo de vida que acabo de adoptar y que consiste en un equilibrio de fuerzas concurrentes en un punto que es mi cuarto, considero resueltas de antemano todas las questiones que puedan presentárseme... Algunos les extraña que dé a lado a ciertas mujeres, que podría cultivar sin molestias y sin grandes gastos; a otros que rehuse ciertas invitaciones y evite otras para comer; o que no tenga amistades, especialmente con los compañeros de carrera, con los que hablo de higos a brevas; pero yo digo que todo llegará a su tiempo sin precipitaciones y con esto me disculpo.

Al mismo tiempo delinea sus planes profesionales:

Ahora... si quisiera podría pedir una vacante que hay en Cardiff, y por permuta podría pasar también a Glasgow y Newcastle; como estoy en un buen puesto tengo facilidad para permutar, porque en nuestro cuerpo las plazas mejores son las más próximas a

30 Carta del 7 de octubre. Es la primera vez que Ganivet nombra a Amelia Roldán desde su llegada a Amberes. Penetramos un sentimiento similar respecto a la patria en este párrafo del 18 de octubre: "Puedes figurarte cuanto te agradezco tu última remesa de noticias frescas, que deseo no sean las últimas, pues no estoy ya tan desesperado que desista de saber algo referente a mi querida patria, que ahora empiezo a comprender y a amar". 
España o las que gozan de más extras... Veremos en estos cuatro años las vueltas que da el mundo y las que yo doy. No pienso apresurarme, porque deseo conocer bien este país y Holanda y porque desde el punto de vista material no puedo estar quejoso... Si al cabo de uno o dos años salgo bien cubierto de carnes (ya estoy bastante grueso) y con un baúl mundo! bien repleto de ropa interior y exterior no se puede decir que he perdido el tiempo ${ }^{31}$.

Su propio aspecto lo satisface con la flamante existencia que lleva; así se considera menos "feo" y exclama: ". . todo cambia en la naturaleza y yo también; estoy muy grueso, la barba se me ha cuadrado y alargado y el conjunto físico, realzado por el fondo moral no es nada despreciable, sobre todo ahora que no me trato con nadie y no es posible por ende que nadie me desprecie" 32 . A los pocos días, el 21 de diciembre, obtenemos del granadino un párrafo cuya naturaleza se repetirá con frecuencia en años posteriores:

Ya habrás visto que no me pasa nada gordo ni flaco; es cierto que he tenido un acceso de rabia reconcentrada; pero ya pasó sin dejar rastro. Acerca de tan interesante suceso te diré solamente que se presentó sin motivo, como un síntoma accidental de mi aclimatación y su forma fue la de misantropía y odio a la luz. Yo creo que todo ello nace de que siento pocas ganas de tratarme con nadie y como esto es imposible y hay que soportar el trato de algunos prójimos, y no sólo el trato sino la chismografía menuda que de él se desprende, pues sabido es que el grueso de los humanos se preocupa de miserias y se mueve en virtud de causas segundas y aun terceras y cuartas, resulta que se va almacenando la bilis y cuando no cabe dentro, sale con violencia a la primera ocasión que se ofrece.

Sobrevienen ahora los años 1893, 1894 y 1895, parcialmente conocidos merced a las 31 cartas publicadas en el Epistolario, que representan fielmente la sensibilidad de Ganivet en la época. La recopilación inédita nos enseña que 1893 empieza, como 1892, con un resumen anual firmado el $1 \%$ de enero por Navarro en su 50a "causerie", donde se lamenta de la marcha al extranjero de Ganivet, quien ha sido el elemento formativo de su vida. El granadino

31 Carta del 8 de noviembre de 1892. En una "causerie" sin fecha, pero seguramente de mediados de noviembre de 1892, Navarro menciona que José Cubas vive en la calle de Jacometrezo, 62, 2 derecha, dirección que luego será la de Pío Cid.

32 Carta del 12 de diciembre de 1892. Su opinión respecto a Taine ya no es tan entusiasta: "Por cierto que he pasado la vista sobre la obra de Taine para refrescar ideas y ahora con más datos a la vista la encuentro falsa. La idea que da de la pintura de los Países Bajos se parece a las imágenes que producen los espejos cóncavos o convexos; son deformes, pero con deformidad regular y proporcionada". 
continúa difundiendo sentimientos de misántropo y anuncia, el 22 de enero, que acaba de mudarse de casa; la nueva es una habitación amoblada en la Rue de la Justice, 39, también frente al Palacio de Justicia, es decir, en las cercanías del Consulado español. El 22 de enero comenta la lectura de La novela alemana del siglo XIX de H. Mielcke, que luego se pondrá a traducir y que marcará el verdadero principio de su entusiasmo por la literatura y filosofías alemanas durante la época de Amberes ${ }^{33}$. Los conocimientos que nuestro autor tiene del inglés y del alemán ya deben ser más que medianos según lo insinúa Navarro en una "causerie" del 31 de marzo ${ }^{34}$. Ambos amigos abordan la literatura germánica del siglo xIx, y las cartas que se cruzan abundan en citas alemanas.

A lo largo del verano de 1893 Ganivet se desespera por abandonar Amberes, a la que imputa su evidente mala salud y el riesgo de contraer "la fiebre fluvial". De ahí provienen múltiples diligencias para residir en Bruselas, pero el 30 de agosto dice que ha regresado de esa capital sin poder conseguir casa: "Parece que el límite de mi resistencia lo he tocado ya y es que no pasarán muchos días, sin que, provisionalmente y mientras llega un cambio más radical, me vea forzado a liar el petate." La situación resulta tan inestable que Navarro dirige las cartas al Consulado de España en Amberes. Hacia finales de año (20 de diciembre), Ganivet manifiesta cierta resignación con las circunstancias que lo rodean, y nos descubre una perspectiva bastante triste:

33 Ganivet mostró siempre gran estabilidad en cuanto al futuro de su carrera. Si el 8 de noviembre de 1892, gracias al párrafo transcrito (véase nota 31 ), averiguamos que considera su permanencia en el cuerpo consular bastante conveniente, en carta del 18 de marzo de 1893 se desdice: “...hoy mismo se me ha ocurrido sucesivamente dos ideas: la primera la de pedir mi cesantía y volver a la madre patria y la segunda pedir mi traslado, si es posible, a Nueva York, donde según noticias queda una vacante. Cada día me encuentro más a disgusto, no por falta de dinero, ni de comodidades ni de nada material sino por menudencias que no merecen siquiera ser referidas". Nuevamente discernimos una oscilación en este comentario del 24 de abril: "La gran ventaja que yo encuentro a esta carrera aparte de otras es que a los cuatro o cinco años se asciende a cónsul y se disfruta un sueldo mínimo... En otras carreras tardas un siglo en llegar a estos sueldos... Suponte que por una serie de calamidades mi familia se viera atascada. En España difícilmente podría sostenerla en ningún puesto que ocupara, mientras que fuera, me seria fácil. El viaje que es lo más caro lo paga el gobierno y lo mismo la vuelta, aunque uno tenga la desgracia de morirse".

34 En la respuesta del 6 de abril Ganivet dice al respecto: "Te advierto que continúo traduciendo la obra de Mielcke y que tengo ya mucho trabajo hecho; si conforme estoy aquí estuviera en un punto de Alemania y pudiera consultar fácilmente sobre asuntos de detalles obras que aquí no puedo tener sino comprándolas, podría escribir sin gran molestia, un trabajo sobre novelistas alemanes modernos. No desisto de la idea, y reúno todos los datos que puedo". 
Si tuviésemos rentas tú y yo no haríamos lo que hacemos; como no hay otro recurso que asegurar la pitanza, condición sine qua non de independencia social, nos sometemos a todo cuanto es necesario, aunque sólo exteriormente para llegar al objeto pretendido, el cual no es otro que conquistar el medio en que hemos de completar nuestra evolución... Si yo no pensara más que en ir saliendo del paso no estaría aquí, ni en Madrid, sino en Granada, donde con mayor seguridad podría dejar correr el tiempo, sin disgustos ni preocupaciones; pero la vida de Granada es para mí lo que es para ti la de Toledo. Por una porción de razones familiares, locales, climatológicas y psicológicas aquello no me gusta para vivir siempre; tengo que buscar otro hueco para instalarme, y para vivir como hombre, no como vegetal, ni como animal, ni como pedregal.

La mudanza de residencia se verifica pero el granadino continúa domiciliándose en Amberes: "Tenía que decirte que en adelante me escribieras a 64, rue Sanderus... Ya te anuncié mi cambio de casa; había tomado cuarto en Bruselas para el 15 de diciembre y tuve que perder los 10 francos que di de señal, a causa del desavío que nos hizo el Canciller. Por ahora no puedo faltar de aquí y como ya había despedido el cuarto, en el que no estaba muy contento... y había tomado otro más pequeño, del género que aquí se llama pied à terre..., me quedé con este último ampliándole con otro que había al lado. Y por ahora ahí seguiré" 35 . Acostumbrado desde sus años en Madrid a vivir sólo con lo indispensable, Ganivet no opondrá mayores reparos a la falta de comodidades de su nuevo hogar. Aconseja a Navarro, por carta del 29 de febrero, que tome precauciones económicas cuando viva en la corte, no obstante las afirmaciones de éste que insiste en haber descubierto las ventajas de una completa sencillez material:

Porque a pesar de tus pretensiones aủn no estabas ni estás habituado a la vida de casa de huéspedes, que tendrías que llevar y hubieras sido para tu familia un cuidado y una carga. Yo tengo el pellejo más duro y no soy nada dispendioso y sin embargo necesitaba auxilios y no espirituales, por lo cual y no por otra razón, decidí largarme, aunque no dejara de serme grato también salir un poco a tomar vientos. Me convendría más, lo comprendo, vivir en Granada o por lo menos en España, pero no veo el modo de conseguirlo, desde el punto y hora en que no quiero depender de mi casa; esto es manía o sistema, pues te consta que el deseo de mi madre es abrirme el bolso; aquí mismo siempre está deseando mandarme, aunque sea por vía de recuerdo; pero yo odio los proteccionismos, quiero hacerme cuenta para este efecto que no tengo a nalario.

35 Carta del 12 de enero de 1894, parcialmente publicada en el Episto- 
die en el mundo, y hasta he renunciado formalmente a la herencia familiar que pudiera caberme.

En la "causerie" del 28 de febrero, Navarro alude a Amelia Roldán, "la interfecta Mme. Ganivet", a la que cree haber visto accidentalmente en Madrid aunque iban ambos muy de prisa: "Si era ella, de lo único que pude hacerme cargo es de que ni en cualidades físicas, ni en recursos indumentarios externos ha adelantado un paso desde los memorables tiempos de la calle de Lope de Vega (períodos carboníferos y pérmico o espérmico)". Ganivet regresará al tema sentimental en un párrafo que parece estar repleto de reminiscencias: "Amores hay que empiezan por idilio y acaban en casa de prostitución, otros hay que empiezan materialmente y después se idealizan y otros (y esto es lo más corriente) sin ser materiales ni ideales comienzan por ser líricos y después se legalizan. En cualquier caso es expuesto anticiparse a los hechos, se entiende cuando el individuo en cuestión es hombre de su tiempo y teme los fallos de la opinión pública"'36.

Al cabo de un permiso de cuatro meses que Ganivet toma de sus deberes consulares, vuelve a Amberes con cierta pesadumbre que resalta si se la compara con las crisis anteriores. Escribe el 16 de abril de 1895:

Nunca me ha seducido la alegría optimista de los inconscientes y cada día me gusta menos. Ni caigo en el otro extremo de preocuparme con reflexiones tristes: nada de eso. Me limito a suicidarme poco a poco, en lo cual no hay poco gusto, pues resulta que cada cosa que matamos en nosotros nos quita una alegría y mil pesares y que si algo merece conservarse, esto, es la facultad de pensar y

36 Carta del 19 de septiembre de 1894. Estas líneas reflejan el gran dilema que tuvo Ganivet con relación a Amelia y a su vida social. Nunca halló para la mujer el lugar que le correspondía como madre de sus dos hijos, y debió alternar su papel entre el de esposa y concubina. Incluyamos un comentario que traduce la intima convicción del granadino sobre el asunto (está en una carta del 19 de junio de 1895): "Yo no simpatizo con muchas cosas de Francia pero me parece que hay un punto en que llevan la razón y es el purgar las cuestiones sentimentales sin hipocresía... Puesto que el matrimonio perfecto, en que hay fidelidad mutua y amor y respeto inextinguible, el matrimonio romántico de Cristo y los caballeros andantes no existe ya y en su lugar ha venido la combinación de intereses; el arreglo del menage, la procreación, etc. porqué no intentar la emancipación sentimental de la mujer, pues la del hombre está conseguida? De ahí ha nacido el divorcio y sale como solución más barata el amor libre coexistente con el matrimonio y saldrá después la abolición del matrimonio mismo. A mí me repugna lo confieso esa solución, del adulterio erigido en regla general y que en París se practica por el $90 \%$ de las mujeres. Admito sí el amor libre pero sin ningún resto de hipocresía; antes de romper con un hombre no es decoroso ni limpio andar con otros, a menos que no se establezca el comunismo puro..." 
de unirse espiritualmente con los objetos, donde reside la única alegría que merezca alegrarnos y la sola gran tristeza que sea digna de entristecernos entre tantas cosas como nos alegran y entristecen por pura estupidez y rutina.

Luego, internado ya en una profunda pendiente nihilista, exclamará: "Yo en confianza, pues ni eso ni otra cosa tendría el mal gusto de hacerlo público, te he dicho que no creo en Dios y así es la verdad y no creo en otra porción de cosas importantes y no me duele nada; antes con haber aligerado mi alimentación me noto cierta satisfacción íntima, cierta frescura interior que a todos mis amigos les deseo. Sospecho que la carga que los hombres arrastran y de la que yo procuro irme librando no aprovecha tanto como la que al burro le echan encima's7.

El 6 de enero de 1896, día del nombramiento, nos da indicaciones de su próximo viaje a Helsingfors, donde se hará cargo del consulado: "Sueldo personal hasta mayo 3,000 francos y después 5,000 , pues hasta los cuatro años no se puede cobrar sueldo de Cónsul. Sueldo de representación 5,875 francos, que creo que habrá que gastar en pieles". Al mes siguiente, el 3 de febrero, da su impresión sobre la capital finlandesa: "Y a todo esto la ciudad debo decirte es un bijou. Aquí paro los pies de fijo, a no ser que me los hagan levantar..."38 Pronto se desvanecerán sus esperanzas de una estadía prolongada en Helsingfors, según nos lo hace constar el 7 de febrero, cuando sufre los efectos de un disgusto con el secretario de la Embajada española en San Petersburgo:

Consecuencias posibles: que me quede aquí hasta mayo y que entonces pida licencia; que me trasladen en mayo a San Petersburgo por dos meses para montar el nuevo engrenaje y después me dejen cesante por supresión, a media paga, hasta que haya vacante; que me boten de aquí en el acto; y por fin que me bote yo mismo cuando tenga fondos para vivir seis $\mathbf{u}$ ocho meses en Madrid por

37 Carta del 14 de agosto de 1895. Estas disquisiciones van acompañadas, en la misma época, por otras de carácter vital: "Y siendo así que tan humano es morirse y terminar para siempre, me confesarás que nada se pierde con anticipar idealmente la muerte, reservándose sólo las más precisas funciones de la vida vegetativa. Esta manera de suicidio es más tranquila que la del suicidio corpóreo y aun que la misma muerte natural".

38 Ahora Ganivet se lanza a componer, en algunas cartas, versos en francés de raíz propiamente verlainiana aunque de incorrección lingüística personal. He aquí algunos ejemplos transcritos textualmente: "Voila que je suis plus triste (Pensées melancoliques et sauvages) // O mon Dieu! que je sens ma bouche amère. / Il me semble qu'on m'a donné un poison / Caché dans quelque souffle de passion / Très subtil et que j'ai aspiré dans l'air. // Je suis blessé mais oui. Je ne sais point / Partout où touche sa main de fine torunure / Je ressens la douleur de la blessure / Il y a des mains qui blessent en caressant". 
cuenta propia. Mis hermanos quieren que me vaya a Madrid y que les pida lo que necesite hasta que yo busque otra salida. La Consular resulta un Abadejo corrompido y apestoso, del que no se puede sacar nada bueno; estoy decidido a dejarla y a buscar un tercer agujero donde meterme ${ }^{39}$.

En agosto de 1898, al llegar a Riga, repite su predilección por Finlandia, cuya capital constituyó sin duda el punto más grato de su carreta. Dice en carta de 8-20 de ese mes: "Pero en fin vivo en mi nueva casa, cerca del Duina, en Hagensberg que es el lado más pintoresco y silencioso de la ciudad. Ésta es grandísima unos 300,000 habitantes algo por el estilo de Copenhague o Amberes. No hace tanto frío como en Helsingfors pero llueve mucho, por la influencia del río que nos atraviesa. Para mí que busco solo un retiro donde me dejen en paz esto es igual que aquello, aunque en punto a seguridad personal, limpieza, orden, etc. no hay nada comparable a Finlandia." El tono más y más misantrópico de sus cartas debe de haber alarmado a Navarro quien le sugiere con mucho tacto (carta de Madrid, 29 de septiembre de 1898): "Tus hermanas, influidas por la extravaganza de que les has dado ejemplo, no saben vivir, ni hacer más que tonterías $\mathrm{e}$ inocentadas, y esto debes tenerlo también muy en cuenta para pensar en volver pronto a su lado, porque son muy buenas, te quieren mucho y merecen que hagas un poco el paterfamilias."

En una tarjeta postal, contestación a una muy elogiosa carta de Navarro sobre Los trabajos, en la que éste saca a relucir las excelentes opiniones que Menéndez y Pelayo, Ortega Munilla, González Serrano y otros tienen de la novela, Ganivet redactará las últimas líneas que contiene la recopilación ${ }^{40}$ :

Recibo tu carta y ya te escribiré enviándote un artículo dedicado a ti. Hoy no lo escribo, pues atravieso una gran crisis espiritual, que si no estuviera tan bien templado me echaría a la fosa. Por fortuna ya empieza a transformarse en trabajo útil y sano. Si ahora escribiera saldría un cienpiés.

39 De alrededores del mes de octubre de 1897 nos viene un soneto, una de las últimas composiciones poéticas de Ganivet, seguramente inspirada por las acciones bélicas de ultramar: "El genio de la guerra // Sobre la dura tierra, en cruz, clavada, / Mostroseme la Imagen dolorida / De la Patria, vilmente escarnecida, / Exangüe, moribunda, abandonada. // Mano aleve en las sombras recatada / La hirió en el pecho con mortal herida; / Y yo sentí escapársele la vida / $\mathrm{Y}$ vi su faz por la aflicción nublada. // Mas luego de la herida que, traidora, / Rasgó el seno de España noble y trágico, / Salió un clamor enérgico y valiente. // $\mathrm{Y}$ al calor de la sangre redentora / Brotó; Patria inmortall por arte mágico, / El Genio de la guerra omnipotente".

40 Tarjeta postal de Riga, con la fecha del correo del 18 de noviembre de 1898 . 
Si ves a Don Marcelino le dirás de mi parte que agradezco mucho su interés y que he pedido los libros, pues aquí no tengo ni un solo ejemplar de ninguno.

Muchos recuerdos y hasta muy pronto.

Angel

La recopilación de Cubas Bliss, que cubre el período 1890-1898, contiene un número mayor de cartas de Ángel Ganivet que de Francisco Navarro Ledesma. Éste, que no estuvo expuesto a los azares de viajes y cambios de casa con tanta frecuencia, pudo conservar un material epistolar más copioso que el autor granadino quien, al parecer, sólo logró guardar con cierta continuidad las cartas de su amigo pertenecientes a 1891-1895. De 1890 y 1897 no quedan vestigios de la correspondencia de Navarro, y los años 1896 y 1898 presentan tres cartas suyas cada uno.

Las cartas de Navarro obedecen a una composición cíclica dividida en tres segmentos: a) "Causeries du lundi", 15 cartas (6-VII1891 hasta 29-X-1891) ; b) "Causeries ésothériques", 85 cartas (30X-1891 hasta 13-IX-1894); c) "Centón epistolar", 12 cartas (I-X1894 hasta 16-III-1895). Las tres series, 112 cartas, poseen gran regularidad en cuanto a fechas, y carecen casi siempre de encabezamientos personales. Las tres que corresponden a 1896, no incluidas en esta clasificación, empiezan con "Hermano Ángel", y las tres de 1898 con "Querido Pío Cid", "Querido Pater" y "Mi querido Pío Cid".

A lo largo de estas relaciones epistolares apunta de modo indudable que Navarro fue el amigo íntimo y entrañable de Ganivet y que José Cubas, Nicolás María López, Daniel Chulví y otros sólo merecieron un afecto reservado de su parte. En algunas ocasiones los citados salen a relucir suscitando comentarios no siempre favorables o simplemente adversos, reciben críticas calculadas de ambos corresponsales o se les determina como amigos incipientes. Aun en esta última categoría Cubas y Chulví resultan ser los más destacados y en varias oportunidades Ganivet pide a Navarro que comparta la lectura de sus cartas con ellos. Es la época en que se entablan apenas los primeros lazos afectivos entre López y Ganivet.

El tono de la correspondencia es frecuentemente jocoso, sobre todo de la parte de Navarro, hasta la partida de Ganivet al extranjero a mediados de 1892. Al cabo de un año la expresión del granadino sufre modificaciones que paulatinamente trascienden en la de Navarro. A fines de 1893 ambos escriben cartas más y más serias que a menudo se confinan en temas metafísicos y artísticos. El período de Finlandia, que Ganivet prefirió a todos los pasados fuera de España, está marcado por una serenidad que permite regresar 
a Navarro a alusiones ligeras, aunque las cartas ya no manifestarán el aire de desenfado del lapso 1890-1892.

Si bien Navarro conoció en todos sus detalles la pasión de Ganivet por Amelia Roldán en Madrid, es probable que haya ignorado hasta tarde el primer viaje que la mujer hizo a París y luego a Amberes. Sería erróneo suponer que esta omisión fue total, pues sin duda hubo conversaciones entre los dos amigos en España. Navarro no se interesará más por las menudencias sensuales de su corresponsal a partir de 1895; el silencio indica seguramente un entendimiento previo, pero no deja de ser curioso comprobar que, después de la mencionada "causerie" del 28 de febrero de 1894, no consagre ninguna frase epistolar a la Roldán. Tal vez percibió que el tema desagradaba a Ganivet, quien lo pasa de largo en su respuesta.

El gusto literario de Ganivet y Navarro coincidió en lo esencial, si bien el granadino, algunos años mayor, tendrá a su cargo una verdadera tarea docente. Ocurrió, sin embargo, un cisma con la aparición de $L a$ conquista, que Navarro recibió mal. Numerosas páginas de Ganivet trataron de defender su posición de autor, pero infructuosamente.

El epistolario denota bastante desprecio por "Clarín" como hombre, aunque reconociéndole talento, y cierta benevolencia hacia la Pardo Bazán, que no obstante constituye el centro de las ridiculizaciones de Navarro. Otras figuras literarias de interés merecen una atención secundaria; una que otra línea alude a Unamuno, Menéndez, Alarcón. La excepción a esta actitud es Pérez Galdós, ampliamente admirado en muchos pasajes.

Hunter College, New York.

Juan V. Agudiez 